\section{Revista de Literatura, História e Memória}

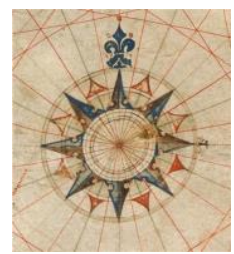

Dossiê: Feminismos e literaturas

ISSN 1983-1498

VOL. 17 - No 30 - 2021

U N I O E S T E / CA S C A V E L - p. 37-49

\title{
FEMINISMOS E LITERATURA DAS MULHERES: CONFIGURAÇÕES POSSÍVEIS E CONSIDERAÇÕES SOBRE O CONTEXTO BRASILEIRO
}

Feminisms and women's literature: possible configurations and considerations on the brazilian context

Alessia di Eugenio ${ }^{1}$

RESUMO: A categoria de "literatura das mulheres" - categoria de análise criada a partir de percursos históricos e sócio-políticos que levaram a reivindicar um espaço específico na organização do saber - poderia ser repensada como um campo aberto, feminista, livre e em transformação. De fato, a criação literária e os feminismos partilham a necessidade da liberdade e da contínua transformação. A análise da produção literária de mulheres que escreveram sobre a época da ditadura - época em que começou o desenvolvimento de um verdadeiro movimento feminista no Brasil - ajuda a refletir sobre presentes e possíveis relações entre os feminismos militantes, as influências feministas e a criação literária.

PALAVRAS-CHAVE: Literatura das mulheres; Feminismos; Criação literária; Literatura brasileira.

ABSTRACT: The category of women's literature could be rethought as a feminist and open field as well as in transition. This category of analysis was created from historical and socio-political paths that led to claim a specific space in the organization of knowledge. Indeed, literary creation and feminisms share the same need for freedom and constant transformation. The analysis of literature produced by women that wrote about the dictatorship period which coincides with the rise of feminist movements in Brazil, helps to reconsider current and possible links between militant feminisms, feminist influences and literary creation.

KEYWORDS: Women's literature; Feminisms; Literary creation; Brazilian literature.

\section{REPENSAR A CATEGORIA DE “LITERATURA DAS MULHERES”}

Cada vez que se reflete acerca da relação entre criação literária e criação das mulheres é preciso resolver, antecipadamente, vários perigos essencialistas e diferentes questões de definição no uso das categorias de referência. Em que sentido podemos falar de uma "literatura feminina" ou das mulheres? Hoje, seria preferível falar de literatura das mulheres e não utilizar o adjetivo "feminina" porque, como reconstrói Marcia Tiburi no recente texto Por um feminismo em Comum, o termo foi criado pelo patriarcado para docilizar as pessoas marcadas como mulheres, seguindo um regime estético-moral (TIBURI, 2018, p. 23). Além

\footnotetext{
${ }^{1}$ Pesquisadora no Departamento de Línguas, literaturas e Culturas Modernas da Universidade de Bolonha. Atua no campo dos estudos culturais e descoloniais brasileiros e atualmente trabalha sobre memória e escrita das mulheres sobre a ditadura militar brasileira. alessia.dieugenio2@unibo.it
} 
disso, o termo "mulher" é uma marcação do patriarcado que, porém, foi ressignificado no feminismo (TIBURI, 2018, p. 19), bem além da identificação num sexo biológico ou numa rígida categoria de gênero. Portanto, uma obra literária produzida por uma "mulher" poderia, hoje, não remeter a uma clara filiação sexuada. A mesma reflexão atravessa outros tipos de filiação, como a da nacionalidade. Por exemplo, quando podemos falar de uma obra literária italiana? A literatura produzida por pessoas nascidas ou criadas na Itália, filhos/as de imigrantes e desprovidos/as de cidadania italiana segundo a lei do Estado, ou a literatura produzida por imigrantes que moram e escrevem na Itália há muitos anos, pode ser reputada literatura italiana? Cada categoria de pertença tem limites e deve ser considerada em relação à transformação dos tempos e das sociedades. Também, além das questões relacionadas com a palavra "mulher", permanece a pergunta sobre a legitimidade de utilização dessa categoria relativa a uma suposta especificidade de criação das mulheres. O risco é sempre a reprodução - mesmo que involuntária - de uma função normativa que estabelece determinados traços característicos da arte literária das mulheres (no campo da expressão, nos temas e no estilo). Contudo, é também verdade que podemos detectar formas de expressão, temas, escolhas comuns a alguns espaços e alguns tempos sem a necessidade de estabelecer rígidas categorias que pretendam se tornar leis de interpretação fixas, imutáveis e válidas para todos os tempos e todos os espaços.

Vale lembrar que a historiadora Michelle Perrot, num célebre ensaio de 1989, utilizou a expressão "memória feminina" para afirmar que a memória, como forma de relação com o espaço e o tempo, é profundamente sexuada e se constitui através de operações imbricadas nas relações masculinas/femininas reais (PERROT, 1989). Essa expressão poderia ser questionada hoje, mas deve ser entendida levando em conta o momento histórico e o sentido em que foi proposta. A ideia de uma "memória feminina", juntamente com novos estudos e com as conquistas dos movimentos feministas dos anos Setenta, promoveu um desenvolvimento diferente da história das mulheres que visava considerá-las como sujeitos históricos que têm um papel político nos acontecimentos da história humana, e não apenas como sujeitos que querem afirmar uma memória e história específicas da própria condição diferencial (familiar, afetiva, maternal). É preciso utilizar as categorias de análise - sempre convenções não abrangentes - considerando-as em transformação e seguindo uma perspectiva de essencialismo estratégico (SPIVAK, 1990).

Hoje, seria preferível falar de "memória das mulheres", entendendo a palavra "mulher" no sentido mais amplo do termo. Mulher é sobretudo "uma expressão básica, um signo de luta" (TIBURI, 2018, p. 21). Neste sentido, poderíamos falar de "literatura das 
mulheres", abrindo os horizontes de reflexão tanto levando em conta quem escreve, além da filiação sexuada, como refletindo sobre temas e perspectivas presentes nas obras. Poderíamos considerar as mulheres como um sujeito (de luta) - em construção e desconstrução - que com a criação literária tenta abolir as normas de criação do patriarcado e visibilizar temas e perspectivas invisibilizados ou sub-representados. Por tal razão, olhando desta ótica e propondo uma reconsideração desta categoria analítica à luz de novas visões e condições socioculturais, a "literatura das mulheres" tem muito a ver com o feminismo ou, melhor, com os feminismos.

O objetivo deste ensaio é repensar esta categoria e analisar a relação entre feminismos e criação literária, levando em conta algumas reflexões sobre o contexto feminista e literário brasileiro.

\section{OS FEMINISMOS E A CRIAÇÃO LITERARIA DAS MULHERES}

Utilizar o plural, falando de "feminismos", aparece hoje indispensável, como lembra a filósofa Djamila Ribeiro no texto O lugar de fala (2019), publicado pela editora Polén, numa coleção que - não por acaso - é intitulada "Feminismos Plurais". Os feminismos são tantos e tão diferentes (por conta das reivindicações, dos lugares, dos tempos, das práticas etc.). E existem também tipos de feminismos, como o feminismo neoliberal, que representam um obstáculo ao radical processo contemporâneo de emancipação das mulheres, como defendem Cinzia Azzurra, Tithi Bhattacharya e Nancy Fraser in Feminism for the 99 Percent. A Manifesto (2019), e feminismos burgueses que precisam ser problematizados e criticados, como afirma Françoise Verger em Un féminisme décolonial (2019).

Todavia, quase todos os feminismos são unidos pela capacidade de "desativar o dispositivo do poder da dominação masculina patriarcal” (TIBURI, 2018, p. 18), de emancipar e libertar as mulheres. A declinação ao plural se inscreve na relação entre feminismo, criação e desejo que permite uma contínua e saudável redefinição do termo:

O feminismo se inventa e se reinventa a cada vez que surge uma nova feminista, a cada vez que surge um novo coletivo, a cada vez que as feministas produzem o feminismo que desejam (TIBURI, 2018, p. 19).

Então, os feminismos mantêm uma ligação estrutural e fundamental com a criação estão em contínua reinvenção - e com a liberdade, dois aspectos fundadores também da arte. Contudo, existem algumas posições que não concordam com a ideia de um caráter inventivo 
e livre em comum entre arte e feminismo.

Um interessante ensaio de Françoise Collin, Texualidade da liberação e liberdade do texto (publicado em 1994 e republicado em Cadernos de Crítica Feminista em 2010), coloca diferentes questões apresentando um ponto de vista que, diferentemente dessa reflexão, não reconhece a capacidade de transformação e flexibilidade dos feminismos. A autora lamenta a progressiva transformação do feminismo num saber estruturado - uma nova ciência representada pelos estudos feministas - que chegou a consenso, mas se tornou quase dogmático, estático, ortodoxo e, portanto, em contradição com os princípios libertadores que o geraram e a liberdade que ele pretende promover. No "progresso" do feminismo, em termos de lugar na organização do saber, mas também de leis e funcionamento das instituições políticas, "alguma coisa se perdeu" (COLLIN, 1994, p. 144). Essa constatação gera preocupações relacionadas ao campo da arte das mulheres. Se a arte é, por definição e segundo a autora, criação livre e libertadora que não está submetida a partidos e finalidades uma "finalidade sem fim", segundo os termos definidos por Kant -, seria a arte incompatível com esse feminismo? "Seria o feminismo incompatível com a criação, se esta não estiver sob condição?" (COLLIN, 1994, p. 145). Essas perguntas conduzem a autora a lembrar a velha concepção da "arte militante", segundo a qual, em nome de ideais defendidos e considerados como supremos, a arte se tornava um instrumento a serviço da "revolução" (a "arte proletária"), do Estado etc. E, seguindo esse argumento, afirma:

No feminismo, estamos longe desse militantismo, mas não se deve subestimar o risco de um desvio, pelo menos ideológico, quando a arte só é autenticada como arte de mulheres, e melhor ainda como arte feminista, e são privilegiadas as artistas que reivindicam esse termo (COLLIN, 1994, p. 144).

$\mathrm{Na}$ realidade, esse discurso abrangeu de muitas maneiras o feminismo. Por exemplo, Patrícia Galvão, escritora e feminista que militou no PCB nos anos da ditadura Vargas, foi por muito tempo considerada marginalmente no cânone literário brasileiro porque os seus textos eram acusados de ser marcados por um excessivo militantismo político-partidário que prejudicava a qualidade das obras. Se é verdade que a qualidade literária deve sempre ser questionada, podemos, todavia, realmente considerar condicionada e desprovida de liberdade uma arte alimentada pelos ideais políticos específicos de quem escreve? A qualidade literária deve ser necessariamente prejudicada pela vocação política? Os critérios que aplicamos para avaliar a qualidade literária são flexíveis, capazes de transformação, suficientemente amplos 
e, sobretudo, abertos ao questionamento? Recentemente, graças também à publicação do texto Pagu vida-obra de Augusto de Campos (2014), a escritora Patrícia Galvão foi reconsiderada, justamente afirmando que é preciso reler a trajetória da sua produção tentando criar um novo vocábulo - vida-obra - para nomear a sua forma específica de criação literária e as condições originais que a geraram.

A relação entre arte e política, desde sempre, causou polêmicas e desentendimentos. Recentemente, o escritor e crítico literário italiano Walter Siti lançou uma publicação intitulada Contro l'impegno. Riflessioni sul Bene in letteratura (2021) que, refletindo sobre um outro contexto e panorama literário, coloca essas mesmas inquietações. Siti afirma que muitos célebres escritores italianos contemporâneos (Murgia, Saviano, Carofiglio entre outros), com maior ou menor consciência, renunciaram à verdadeira escrita literária em nome do que ele chama de "neo-impegno" ("neo-engajamento"). Essa postura determinaria uma escrita que tem como objetivo a transmissão do conteúdo para um público mais amplo possível e a eficácia ética imediata, abdicando do trabalho da língua. Esses textos seriam caraterizados pela simplicidade sintática, pela trama melodramática, pela falta de densidade textual, entre outros, e se tornariam assim "webáveis", simplificados, facilmente traduzíveis e fragmentáveis, interiorizando o imperativo da mídia e da comunicação. As conclusões parecem ser implacáveis: a sobrevivência da verdadeira literatura - como também da verdadeira crítica literária - é ameaçada pelos efeitos de novas preocupações ideológicas e políticas. Além das avaliações sobre o que é considerado literatura e crítica literária por Siti formas historicamente determinadas e ligadas à configuração burguesa do século XX de saberes em transformação, como afirma Giacomo Tinelli (2021) -, é a concepção do relacionamento entre literatura e política a estar em jogo. Nas posições de Collin e Siti, o engajamento, ligado à própria condição ou a diferentes tipos de vocações políticas, por um lado parece prejudicar a radical liberdade da artista na busca do novo, do inesperado, do desviante, do original, por outro lado parece comprometer a profundidade e qualidade da literatura. No entanto, este discurso não corre o risco de cair numa visão idealizada/alienada da "artista livre", como se ela não fosse parte de tempos, lugares, ideias/ideais e/ou modas e mercados? Também, não é possível vislumbrar o legado de certas perspectivas positivistas que entendem o saber e a arte como algo produzido a partir de um "fora" inexistente? A liberdade criativa é incompatível com o posicionamento, a parcialidade, a posição-postura política e ética no mundo?

A artista e professora Grada Kilomba, no texto Memórias da Plantação (2020), retoma e opõe o conceito de "subjetividade consciente", no âmbito da pesquisa acadêmica, à ideia, 
ainda presente, de que é preciso distanciamento emotivo, social e político para fazer investigação científica de qualidade (KILOMBA, 2020, p. 85). Da mesma maneira, seria preciso criar outros termos para não qualificar como menor e menos livre a arte produzida a partir de um posicionamento ou engajamento político, social e emotivo explicito. Todas as obras literárias que foram elaboradas a partir de preocupações e posições declaradamente feministas - por exemplo as de Patrícia Galvão - não são menos livres do que obras que não reivindicaram essa filiação. A arte é criação libertadora alimentada por paixões e pulsões livres, mas também por ideais, valores e posições (políticas e éticas) que podem ser livres de igual forma. O compreensível medo de tornar a arte mero instrumento ideológico sem qualidade tem, porém, o risco de deixar-nos recair nos mitos do distanciamento, da neutralidade, do "além" das relações de poder e domínio em que também a criação está inscrita. Porque o posicionamento e o engajamento feministas são considerados, por exemplo, por Collin, um limite que impede a liberdade criativa das artistas e que cai na reprodução de uma suposta ortodoxia do pensamento feminista? Acreditamos que o diagnóstico do feminismo contemporâneo proposto por ela é discutível.

A história do feminismo ocidental mostra que o caminho feito é cheio de transformações, discussões e controvérsias, inclusões e revisões. Os coletivos feministas são tantos e tão diferentes como as perspectivas de luta defendidas (separatistas, ligadas à diferença sexual, LGBTQIA+ etc.). Não existe tema feminista que não seja debatido e considerado diferentemente por distintos grupos de feministas (maternidade, "identidade de gênero", prostituição etc.), e não existe teoria feminista que não seja elaborada no constante confronto com novas e outras perspectivas feministas (por isso falamos de feminismo da diferença, feminismo intersecional, feminismo negro, feminismo decolonial etc.). Talvez os movimentos feministas sejam o exemplo mais vivaz de flexibilidade e capacidade de introduzir o novo, de elaborar teorias abertas e nômades, de criar diferentes "escolas", posições e saberes em constante discussão e transformação, longe da ideia de uma rígida ortodoxia.

A crítica, talvez dirigida a experiências feministas específicas, não pode se tornar uma apreciação negativa da complexa e riquíssima história dos feminismos contemporâneos. $\mathrm{O}$ texto de Marcia Tiburi é dedicado a traçar um manifesto desses feminismos, lembrando a capacidade que sempre tiveram de se reinventar, o seu caráter aberto, transformador, dialógico justamente pela constante presença de dissonâncias: "Feminismo é um significante que preenchemos com nosso desejo, nossos saberes e ignorâncias" (TIBURI, 2018, p. 20). Portanto, o caráter inventivo e livre dos feminismos pode, com certeza, alimentar - de forma 
implícita ou explícita - muitas obras literárias das mulheres sem prejudicar a sua liberdade criativa.

Esclarecido esse ponto, é também importante especificar que não apenas as obras que reivindicam uma filiação feminista podem ser consideradas feministas e pertencentes à categoria de "literatura das mulheres" que estamos pensando, mas também obras escritas por mulheres que incorporaram algumas perspectivas feministas - não necessariamente em acordo com outras - ou escolheram visibilizar temas e subjetividades sub-representados pelas formas de criação dominante. É preciso abolir a ideia de um militantismo feminista teórico e prático oposto à criação artística/literária das mulheres. Foram precisamente esta imagem negativa e estereotipada da militância como ortodoxia, rigidez, teoria-prática distante das formas criativas livres e a imagem igualmente negativa e estereotipada da "mulher feminista" que causaram o afastamento de tantas mulheres deste termo e dessa reivindicação. Tantas autoras que não reivindicaram o título de feminista produziram obras densas de reflexões feministas, na luta contra formas de autoritarismo e violência patriarcal. Acreditamos que o impacto do caminho feminista se encontra sobretudo nessas influências indiretas. A falta de uma autodeclaração torna esses trabalhos menos feministas? O papel da crítica é o de analisar esta produção criando um campo de análise - e uma categoria crítica suficientemente abrangente - que inclua todas essas possibilidades. A literatura das mulheres brasileiras oferece um interessante exemplo de reflexão.

\section{FEMINISMOS E LITERATURA DAS MULHERES: REFLEXÕES BRASILEIRAS}

Constância Lima Duarte, no ensaio Feminismo e literatura no Brasil (2003), identifica quatros momentos áureos (“momentos-ondas" em torno de 1830, 1870, 1920, 1970) na história do feminismo brasileiro e tenta analisar as suas conexões com a produção escrita de mulheres brasileiras (declaradamente) feministas. Na conclusão, a autora cita e critica a posição de quem fala, relativamente à nossa contemporaneidade, de "tempos pós-feministas", como se as reivindicações tivessem sido atendidas e o feminismo fosse ultrapassado. Acreditamos que, obviamente, é bem mais fácil identificar conquistas e linhas de interpretação da história do feminismo e muito mais complexo interpretar movimentos e dinâmicas - múltiplas e mutantes - do presente. No campo da arte e da sua relação com os feminismos, uma das dificuldades está na convicção, por exemplo, defendida por Collin já nos anos Noventa, de que há poucas artistas que reivindicam para si o título (de feminista e também de mulher) (COLLIN, 1994, p. 144) e que encontram no feminismo o motor 
inspirador da própria criação. É precisamente essa posição que queremos discutir recorrendo ao caso específico brasileiro.

No Brasil, pode-se falar de nascimento de um verdadeiro movimento feminista a partir dos anos de 1960/1970: “o novo feminismo nasce na ditadura” (PINTO, 2003, p. 40), surge como feminismo de esquerda (SARTI, 2001), comprometido com as lutas pelas liberdades democráticas e pela anistia, e se desenvolve como consequência da resistência das mulheres "depois da derrota da luta armada e no sentido da elaboração política e pessoal desta derrota" (SARTI, 1998, p. 3). A partir de 1975, ano em que foi instituído pela ONU o Ano Internacional da Mulher, foram publicados os primeiros jornais nacionais dirigidos por mulheres que se autodenominavam feministas (entre eles os jornais Brasil Mulher, Nós Mulheres e Mulherio) e que contribuíram para a construção do discurso feminista no Brasil (CESTARI, 2013). A experiência desses anos foi fundamental pela elaboração de uma consciência feminista: muitas mulheres que militaram nas organizações clandestinas tiveram que enfrentar o machismo dos seus companheiros e a subestimação das suas capacidades físicas e intelectuais (TELES, 1999, p. 70), além da repressão política especifica reservada às mulheres. Também, a volta das mulheres que foram exiladas ou que escolheram se exilar, graças à anistia de 1979, foi igualmente fundamental nesse processo: essas mulheres foram influenciadas pelo feminismo internacional, criaram fóruns e redes internacionais para refletir sobre a condição da mulher no Brasil - como testemunha o livro pioneiro Memórias das mulheres do exílio (obra coletiva publicada em 1980) - e, sobretudo, ajudaram na introdução da questão racial, antes negligenciada pelo feminismo brasileiro. Lélia Gonzalez, no fundamental ensaio Por um feminismo afro-latino-americano (publicado em 1988), sustenta essa tese e afirma que muitos exilados "(visto como brancos no Brasil) foram objetos de discriminação racial no exterior" (GONZALEZ, 2018, p. 49) e, voltando para o Brasil, contribuíram para o questionamento do mito da democracia racial. Portanto, a partir dos anos 1980 o feminismo brasileiro conheceu um novo e verdadeiro desenvolvimento e enraizamento.

Todavia, nesses anos quase não aparecem textos literários publicados por mulheres que tratam também da condição e do protagonismo das mulheres na ditadura (as motivações podem ser procuradas no silenciamento inicial das suas experiências e do seu papel histórico e político). As poucas exceções (por exemplo Lygia Fagundes Telles, Ana Maria Machado, Heloneida Studart) mostram que o feminismo, nestes anos de plena consciência das reivindicações, estava amplamente presente como motor da escrita e como referência das autoras, mas de forma não sempre explícita. Por exemplo, a escritora Heloneida Studart era 
declaradamente feminista e militante. Em 1974 publicou um pequeno escrito, intitulado Mulher, objeto de cama e mesa, que, questionando a sociedade patriarcal e a "escravidão" das mulheres, se tornou imediatamente uma referência importante para o movimento feminista e chegou à 27a edição. Em 1975 participou do Congresso Internacional da Mulher no México e logo depois fundou, no Rio de Janeiro, o primeiro centro dedicado à mulher no Brasil: o Centro da Mulher Brasileira (CMB). Studart é autora de três romances da denominada "trilogia da tortura": O pardal é um pássaro azul, de 1975, Estandarte da agonia, de 1981, e O torturador em romaria, de 1986. O protagonismo das mulheres e a subversão de estereótipos de gênero são os alicerces de todos esses livros. Diferentemente, Ana Maria Machado, autora do texto Tropical Sol da Liberdade, publicado em 1988 e dedicado à época da ditadura, não se descreve como feminista. Numa entrevista em que lhe perguntaram se a sua obra (e ela) pode ser considerada feminista, afirma:

O crítico diz o que ele quiser. Ao longo da minha vida, fui muito combativa e militante, mas nunca fui partidária. Nunca pertenci a nenhuma organização. Não sei se sou feminista ou socialista. Sei que estou próxima dessas duas características, mas não vejo isso como rótulo. Além do mais, não tem como na minha geração uma mulher com a minha história, que viveu no Brasil em que eu vivi, não ter uma atitude feminista. Mas esse rótulo não me incomoda (ALVES, 2016, s. p.).

A autora, por um lado, confirma - mesmo que de forma negativa - a autonomia da crítica em relação às perspectivas e às convenções das autoras, por outro lado confirma a influência fundamental e inegável do feminismo na criação das mulheres da sua geração, recusando a necessidade de uma autodefinição explícita como signo de uma atitude feminista na vida e nas obras. O feminismo, implicitamente ou declaradamente, é parte do caminho de vida e criação dessas autoras.

A partir dos anos 1990 e sobretudo nos anos 2000 a situação mudou e começaram a aparecer muitos romances escritos por mulheres sobre a ditadura, muitas vezes com enredos em que as mulheres são protagonistas no contexto daqueles anos ou no presente influenciado pela herança da época. As autoras desses textos são tanto mulheres que viveram nos anos de chumbo, mas decidiram escrever muitos anos depois (Maria Pilla, Maria Valéria Rezende, Sonia Bischain, Maria José Silveira, entre outras), como jovens mulheres que não viveram na idade adulta na época da ditadura (Adriana Lisboa, Luciana Hidalgo, Paloma Vidal, Liniane Haag Brum, Guiomar de Grammont, Claudia Lage entre outras). Além de mulheres que foram militantes de movimentos feministas na época da ditadura (por exemplo, Maria Pilla, que 
escreveu o livro Volta semana que vem, em 2015), todas as mulheres dessa geração e da geração seguinte incorporaram de alguma forma as lutas feministas nas suas obras. Contudo, os modos pelos quais essa influência se manifesta, na literatura e nas declarações das autoras, são diferentes e não lineares.

A escritora Maria Valéria Rezende, da geração que viveu a época da ditadura, confirma as influências implícitas, até mesmo inconscientes, dos feminismos, também os do presente, na sua produção literária. Ela era educadora popular e militante nos anos da ditadura e é autora do romance Outros Cantos, de 2016, dedicado a narrar a história de uma educadora popular e militante clandestina naqueles anos. Entrevistada sobre o novo livro, Carta à rainha louca, de 2019, que traz histórias de mulheres brasileiras do período colonial, afirma:

Não pensei "vou fazer um livro feminista", mas ele se torna... Demoro muitos anos para escrever um romance. Escrevo três, quatro ao mesmo tempo. Então, o que vai acontecendo enquanto escrevo vai mexendo no meu texto. Mesmo que o texto não se refira diretamente a isso. É o caso desse livro (MORAES, 2017, s. p.).

Nessa fala ela confirma a influência implícita dos feminismos nas suas obras literárias, mesmo quando os temas feministas não são pensados como centrais na trama. Essa declaração nos ajuda a pensar o feminismo como algo que afetou as vidas das autoras bem além do campo específico das reivindicações militantes e explícitas.

Um outro exemplo é fornecido pelas declarações da escritora Claudia Lage, jovem autora do romance $O$ corpo interminável (publicado em 2019), que se confronta com a herança da época da ditadura nas gerações dos filhos, deixando amplo espaço às experiências e memórias das mulheres. Numa entrevista afirma:

Toda escritora e escritor tem seus interesses, assuntos específicos que despertam e que levam à escrita, é uma fagulha que acende, é uma voz interior, e o que faço é dar espaço a essa fagulha e ouvir essa voz. É o que digo a mim mesma, escreva o que quiser, sobre o que quiser, como quiser, o que inclui, no meu caso, escrever sobre mulheres também, já que tudo que é humano é universal. ${ }^{2}$

Nesse caso, o seu interesse em escrever sobre mulheres é considerado como uma vocação específica e livre entre outras, não necessariamente como um posicionamento político explícito e militante. Então, os temas feministas entram nas criações literárias dessas mulheres seguindo

\footnotetext{
${ }^{2}$ Entrevista disponível no site do grupo editorial Record. Disponível em: https://www.record.com.br/cincoperguntas-para-claudia-lage-autora-participa-hoje-da-semana-amazon-de-literatura/. Acessado em: 28/08/2021.
} 
posicionamentos, inspirações, vocações e reivindicações diferentes.

\section{CONSIDERAÇÕES FINAIS}

Além da militância ativa ou não em organizações feministas, e além da perspectiva explicitada pelas autoras sobre o processo de criação, nos textos dessas mulheres é central o protagonismo feminino, os acontecimentos históricos são narrados e reconstruídos a partir da perspectiva das mulheres, são questionados os estereótipos ligados aos papéis de gênero, e são visibilizadas experiências de luta das mulheres, exibindo críticas ao autoritarismo patriarcal. Então, sem dúvidas, os textos são afetados pelas perspectivas abertas pelos feminismos.

Avaliando a relação entre obras literárias e feminismos, não acreditamos que seja fundamental a autodefinição das autoras, as escolhas militantes ou não de cada uma, não porque a biografia e os posicionamentos das autoras sejam insignificantes nessa relação - ao contrário, revestem grande valor -, mas porque muitas mulheres são e podem ser feministas nas ações cotidianas, na vida, no trabalho e na criação sem necessariamente reivindicar esse título ou ter uma "perspectiva militante". As nossas perguntas deveriam ser: quantas obras literárias, criadas a partir de perspectivas livres e coerentes - militantes ou não, explícitas ou não - apresentam temas e óticas feministas? A liberdade da criação aparece como inspiração da escrita tanto nas obras de quem reivindica um específico posicionamento político quanto naquelas que surgem com outros pressupostos. É preciso defender a liberdade e a importância do engajamento feminista declarado sem condenar as criações que podem se tornar feministas sem esse objetivo prioritário. Repensar as relações entre militância e criação significa, hoje, incluir nas produções feministas todas as mulheres que contribuem na difusão de ideias e perspectivas feministas com coerência de vida. Isso significa que as biografias são fundamentais, mas não podem responder a esquemas rígidos. As motivações que levam as pessoas a participar ativamente da vida política são muitas e complexas, e, certamente, não podem ser julgadas simplesmente com condenas ou aplausos. Os feminismos, sendo diálogo e renovação, nos ensinam a debater constantemente com todas as produções e criações que, de formas diferentes, refletem sobre condições e experiências das mulheres. Praticar esse diálogo ajudará a aumentar a consciência - e a importância - dos posicionamentos políticos e éticos nas nossas sociedades.

De fato, em muitos lugares, nasceram recentemente vários percursos que tentam defender o posicionamento das artes e das artistas. Em 2020, vários artistas e trabalhadores do espetáculo criaram, na Itália, um blog, chamado $O$ campo inocente, para refletir sobre a 
questão da violência, do sexismo e da precariedade no mundo artístico, lembrando que "a arte não é um campo inocente" ${ }^{3}$ Esse coletivo realiza pôsteres com frases simples que tentam desmontar narrativas dominantes sobre o campo da arte. "A arte não é um outro mundo", a arte é radicada nas relações de poder deste mundo e, por isso, nenhuma obra de arte pode ser julgada como se o seu autor fosse intocável. Nenhuma autora pode ser premiada pela sua obra se reproduz na vida relações de violência e exploração. Essas reflexões nos ajudam a repensar a categoria de "literatura das mulheres" - categoria de análise criada a partir de percursos históricos e sócio-políticos que levaram a reivindicar um espaço específico na organização do saber - como um campo aberto, feminista, livre e em transformação que, independente do posicionamento explicito das autoras, precisa de coerência de vida. Talvez, este seja o sentido mais profundo da luta feminista e da liberdade da criação.

\section{REFERÊNCIAS BIBLIOGRÁFICAS}

ALVES, Alan Tiago. "Alarga horizontes" diz Ana Maria Machado sobre literatura na Flica. Globo, 2016. Disponível em: http://g1.globo.com/bahia/noticia/2016/10/alarga-horizontesdiz-ana-maria-machado-sobre-literatura-na-flica.html. Acessado em: 28/08/2021.

AZZURRA, Cinzia, BHATTACHARYA, Tithi e FRASER, Nancy. Feminism for the 99 Percent. A Manifesto. London: Verso, 2019.

CAMPOS, Augusto de. (Org.). Pagu: vida-obra. São Paulo: Companhia das Letras, 2014.

CESTARI, Mariana Jafet. As mesmas e as novas mulheres do feminismo brasileiro. Estudos Linguísticos, São Carlos, v. 42, n. 3, 2013. p. 1127-1140.

COLLIN, Françoise. Texualidade da liberação e liberdade do texto. Revista Estudos Feministas, Florianópolis, $\mathrm{N}^{\circ}$ especial, 1994. p. 142-150.

DUARTE, Constância Lima. Feminismo e literatura no Brasil. Estudos Avançados, São Paulo, v. 17, n. 49, 2003. p. 151-172.

GONZALEZ, Lélia. Por um feminismo afro-latino-americano. In: HOLLANDA, Heloisa Buarque de (Org.). Pensamento feminista hoje. Perspectivas decoloniais. Rio de Janeiro: Bazar do tempo, 2018. p. 42-56.

KILOMBA, Grada. Memórias da Plantação. Episódios de racismo cotidiano. 2 ed. Lisboa: Orfeo Nego, 2020.

MORAES, Camila. Maria Valéria Rezende: “As pessoas pensam que freiras são bobinhas.

3 Texto disponível no blog "Il campo innocente": https://ilcampoinnocente.blogspot.com/2020/01/?m=0 Acessado em: 10/09/2021.

${ }^{4}$ Ibidem. 
Como podem escrever literatura?". El País, 2017. Disponível em: https://brasil.elpais.com/brasil/2017/02/20/cultura/1487625634 391058.html. Acessado em: 28/08/2021.

PERROT, Michelle. Práticas da memória feminina. Revista Brasileira de História, São Paulo, v. 9, n. 18, 1989. p. 9-18.

PINTO, De Céli Regina Jardim. Uma historia do feminismo no Brasil, São Paulo: Editora Fundação Perseu Abramo, 2003.

RIBEIRO, Djamila. Lugar de fala. São Paulo: Polén, 2019.

SARTI, Cynthia Andersen. O início do feminismo sob a ditadura no Brasil: o que ficou escondido. Texto apresentado no XXI Congresso Internacional da LASA (Associação de Estudos Latino-Americanos), Chicago, 1998. p. 1-12. Disponível em: http://biblioteca.clacso.edu.ar/ar/libros/ lasa98/Sarti.pdf Acessado em: 26/08/2021.

SARTI, Cynthia Andersen. Feminismo e contexto: lições do caso brasileiro. Cadernos Pagu, Campinas, n. 16, 2001. p. 31- 48.

SITI, Walter. Contro l'impegno. Riflessioni sul Bene in letteratura. Milano: Rizzoli, 2021.

SPIVAK, Gayatri C. The Post-Colonial Critic. Interviews, Strategies, Dialogues. Routledge, 1990.

TELES, Maria Amélia de Almeida. Breve história do feminismo no Brasil. São Paulo: Brasiliense, 1999.

TIBURI, Marcia. Feminismo em comum para todas, todes e todos. Rio de Janeiro: Rosa dos Tempos, 2018.

TINELLI, Giacomo. Preoccupanti sintomi stilistici di una scrittura in cerca di attualità. II Manifesto, 4 agosto 2021. Disponível em: https://ilmanifesto.it/preoccupanti-sintomistilistici/. Acessado em: 27/08/2021.

VERGER, Françoise. Un féminisme décolonial. Paris: La Fabrique, 2019. 